\title{
Incidence and assessment of demography-related risk factors associated with pulmonary tuberculosis in Saudi Arabia: A retrospective analysis
}

\author{
Omar S. El-Masry'1, Muzaheed ${ }^{2}$
}

\begin{abstract}
Background \& Objectives: Tuberculosis (TB) is a public health challenge and is endemic in many countries including Saudi Arabia. The disease is a major health concern in the Kingdom because of its dynamic population as resident expatriates are mainly from high TB burdened countries and the mass influx of pilgrims every year in peak seasons for Umrah and Hajj. The objective of the current study was to evaluate pulmonary TB incidence rates and conclude the potential high-risk patients to highlight the burdened regions in Saudi Arabia for the health authorities, which could help to establish policies of infection control as necessary.

Methods: We retrospectively investigated the incidence of pulmonary TB data reported by the ministry of health $(\mathrm{MOH})$ in 2018. We analyzed pulmonary TB incidence data by nationality, age, gender, and region using Chi-square test to identify demography-related risk factors associated with pulmonary TB and its significance.

Results: The results indicated that the incidence of pulmonary TB was significantly higher in males than in females in both Saudi and non-Saudi nationals; the number of cases was particularly high in major cities. Also, infections were mainly associated with certain age groups that were different between the Saudi and non-Saudi nationals.

Conclusion: TB control seems to be facing some challenges in several regions of the Kingdom, particularly major cities. National TB Control Program (NTP) needs to continually evaluate official data to spot high risk groups and factors associated with increased incidence. This will help to improve TB control strategies to contain the disease and approaches its eradication.
\end{abstract}

KEYWORDS: Pulmonary Tuberculosis, Incidence, Risk Factors, Demography, Saudi Arabia.

doi: https://doi.org/10.12669/pjms.38.4.5087

How to cite this:

El-Masry OS, Muzaheed. Incidence and assessment of demography-related risk factors associated with pulmonary tuberculosis in Saudi Arabia: A retrospective analysis. Pak J Med Sci. 2022;38(4):850-854. doi: https://doi.org/10.12669/pjms.38.4.5087

This is an Open Access article distributed under the terms of the Creative Commons Attribution License (http://creativecommons.org/licenses/by/3.0), which permits unrestricted use, distribution, and reproduction in any medium, provided the original work is properly cited.

1. Dr. Omar S. El-Masry, Ph.D.

2. Dr. Muzaheed, Ph.D.

1.2: Department of Clinical Laboratory Science,

College of Applied Medical Sciences,

Imam Abdulrahman Bin Faisal University,

Dammam 31441, Kingdom of Saudi Arabia.

Correspondence:

Dr. Muzaheed

Department of Clinical Laboratory Science,

College of Applied Medical Sciences,

Imam Abdulrahman Bin Faisal University,

Dammam 31441, Saudi Arabia.

E-mail: marasheed@iau.edu.sa

* Received for Publication:

* Revision Received:

* Revision Accepted:
July 29, 2021

November 16, 2021

December 27, 2021

\section{INTRODUCTION}

Tuberculosis (TB) is caused by the airborne infectious pathogen, Mycobacterium tuberculosis. ${ }^{1}$ It primarily infects the lungs causing pulmonary TB and can invade other organs causing extrapulmonary TB (EPTB). ${ }^{2}$ TB is prevalent in all countries and distributed in various age groups. ${ }^{3}$ Of note, $10 \%$ of healthy individuals who are infected with $M$. tuberculosis develop TB within two years. ${ }^{4}$ In addition, the incidence is higher among people with human immunodeficiency virus (HIV) infections. ${ }^{5}$

One-third of world's population is infected with M. tuberculosis, which is ranked among top 10 causes 
of deaths worldwide surpassing HIV. ${ }^{6}$ It is also denoted as the major cause of deaths from a single infectious agent. In 2019, where about 10 million people developed TB and 1.4 million died. ${ }^{6}$ This is equivalent to 130 cases/100,000. The World Health Organization (WHO) indicated that the incidence of TB globally is declining very slowly in recent years and similarly the Saudi Ministry of Health $(\mathrm{MOH})$ stated a slow decline in TB. ${ }^{7}$ However, we would like to notify the readers that this declining rate is variable between different Saudi cities, particularly in the capital city of Riyadh and in holy cities (Makkah and Madinah) during Umrah and Hajj seasons. ${ }^{8}$ Regarding Saudi Arabia, the number of reported TB cases was 3336 in 2014. Saudi Arabia is a global destination where the influx of pilgrims throughout the year confers highly dynamic nature to the population as well as the large proportion of expatriates in the country's population. ${ }^{9}$

Despite of the major measures to prevent and control the spread of tuberculosis, the disease continues to be a serious global public health concern, particularly in the developing countries. ${ }^{10}$ In this respect, the top six TB burdened countries are India, Indonesia, China, Nigeria, Pakistan, and South Africa where infections in these countries account for $60 \%$ of new cases worldwide. India and China account for half of all global TB cases. ${ }^{11}$ It was also reported that pulmonary TB is the most prevalent form of the disease in the northern part of Iran. ${ }^{12}$ Another Middle East country with a high incidence rate as reported in 2014 is Turkey, with $22 \%$ of all reports out of 58252 recorded cases in the Middle East. ${ }^{13}$ Also, the global TB report that was published in 2016 ranked the gulf countries based on the incidence rate of TB, where Kuwait came first with an incidence of 200 cases/million, followed by Saudi Arabia (89/million), and then United Arab Emirates with the least incidence rate (6.8/ million). ${ }^{14}$ Coming to the developed countries, the rates in the United States has declined remarkably to three cases $/ 100000$, which could be attributed to the advanced health care system in the country in comparison to the developing countries. ${ }^{15}$

Regarding mortality, it increases with the presence of comorbidities. ${ }^{16}$ For example, HIV and TB co-infection is an important cause of mortality in HIV patients. ${ }^{10}$ In addition, diabetes mellitus $(\mathrm{DM})$ is associated with an increased mortality rates following TB infections. ${ }^{17}$ In this regard, DM is an established comorbidity that accelerates TB complications and derail its treatment. Likewise, smoking increases the risk of $\mathrm{TB}$ as well as its related mortality rates. To sum up, the mortality predictors include older age, low body weight, rural living, discontinued treatment, EPTB, immunocompromisation, comorbidities, and coinfections, especially HIV infections. ${ }^{9}$

The objective of the current retrospective study was to analyze the reported cases of pulmonary TB to comprehend the epidemiology and ascertain its association with the risk factors that may aid the National Tuberculosis Program (NTP) of the Saudi Arabia to spot high risk groups and figure out the success of infection control measures to revise their policies and measures to combat the disease.

\section{METHODS}

This is a retrospective study that was conducted to analyze official pulmonary TB figures in Saudi Arabia cities that were reported by the $\mathrm{MOH}$ for the year 2018 (https://data.gov.sa/Data/en/ organization/ministry_of_health). The official data figures of pulmonary TB cases were obtained and comprised the figures of 13 provinces and seven districts for Saudi and non-Saudi nationals as well as incidence amongst males and females. Cases were categorized into seven age groups, which were as follows: < 15, 15-25, 25-35, 35-45, $45-55,55-65$, and $\geq 65$ years old. Also, cases were stratified according to gender, nationality, and region to compare the incidence rates between different strata of the study sample. Of note, the status of non-Saudi cases in the $\mathrm{MOH}$ reports was not indicated as being visitors or residents.

Statistical Analysis: The data was tabulated in Microsoft Office Excel and the descriptive statistics such as mean; sum and percent distribution were calculated. The comparison between the incidence rates in different age groups and gender for Saudi and non-Saudi nationals were computed by $\mathrm{Chi}$ Square test using IBM SPSS (Version 23; IBM Corp., Armonk, N.Y., USA). P-value of $\leq 0.05$ was considered statistically significant.

Ethical Approval: This is a secondary data analysisbased study, which does not require to be ethically reviewed and approved as all data are publicly available through the Ministry of Health portal without any reference to personal identifying information of patients, for this reason, IRB approval is not applicable.

\section{RESULTS}

The rate of incidence: The number of cases of pulmonary TB reported by the $\mathrm{MOH}$ in Saudi Arabia cities in 2018 is presented in Table-I. The 
Table-I: Region-wise incidence of Pulmonary Tuberculosis among Saudi and non-Saudi population (2018).

\begin{tabular}{|c|c|c|c|c|c|c|c|}
\hline \multirow{2}{*}{ Region } & \multicolumn{3}{|c|}{ Saudi } & \multicolumn{3}{|c|}{ Non-Saudi } & \multirow{2}{*}{$\begin{array}{l}\text { Total } \\
\text { Cases }\end{array}$} \\
\hline & Male & Female & Total & Male & Female & Total & \\
\hline Riyadh & 255 & 67 & 322 & 241 & 97 & 338 & 660 \\
\hline Makkah & 60 & 27 & 87 & 66 & 41 & 107 & 194 \\
\hline Jeddah & 243 & 56 & 299 & 332 & 119 & 451 & 750 \\
\hline Taif & 14 & 06 & 20 & 16 & 05 & 21 & 41 \\
\hline Madinah & 42 & 19 & 61 & 43 & 17 & 60 & 121 \\
\hline Qaseem & 13 & 06 & 19 & 15 & 05 & 20 & 39 \\
\hline Eastern province & 56 & 20 & 76 & 146 & 28 & 174 & 250 \\
\hline Al-Ahsa & 06 & 02 & 08 & 16 & 05 & 21 & 29 \\
\hline Hafr Al-Baten & 10 & 02 & 12 & 10 & 04 & 14 & 26 \\
\hline Aseer & 15 & 14 & 29 & 34 & 03 & 37 & 66 \\
\hline Bishah & 08 & 05 & 13 & 05 & 05 & 10 & 23 \\
\hline Tabouk & 03 & 03 & 06 & 15 & 03 & 18 & 24 \\
\hline Hail & 06 & 02 & 08 & 06 & 03 & 09 & 17 \\
\hline Northern & 03 & 01 & 04 & 06 & 00 & 06 & 10 \\
\hline Jazan & 38 & 53 & 91 & 87 & 18 & 105 & 196 \\
\hline Najran & 08 & 05 & 13 & 17 & 07 & 24 & 37 \\
\hline Al-Bahah & 09 & 00 & 09 & 10 & 03 & 13 & 22 \\
\hline Al-Jouf & 02 & 01 & 03 & 03 & 00 & 03 & 06 \\
\hline Qurayyat & 04 & 01 & 05 & 10 & 00 & 10 & 15 \\
\hline Qunfudah & 05 & 01 & 06 & 10 & 01 & 11 & 17 \\
\hline Total & 545 & 291 & 836 & 1088 & 364 & 1452 & 2543 \\
\hline
\end{tabular}

${ }^{*}$ Number of cases per 100,000.

results indicated that the highest number of cases amongst Saudi nationals was recorded in the capital city of Riyadh with most subjects being males (79.2\%), which was also the case for Jeddah where males represented most cases $(81.2 \%)$. Overall, the occurrence of infections in Saudi males was higher than that in females, except in Jazan, wherein the percentage of infections in females was $58.2 \%$.

Regarding the incidence of infection in nonSaudi nationals, the highest incidence rate was recoded in Jeddah, followed by Riyadh. Also, the incidence rate was significantly higher $(p \leq 0.001)$ in males than in females representing $73.6 \%$ and $71.3 \%$, respectively. The incidence of infections in males amongst the non-Saudi nationals was higher than that in females in all cities without exceptions. The map in Fig.1 depicts the incidence of pulmonary TB in different cities; the symbols code indicates the magnitude of incidences and classifies them into four different rates.
Assessment of Risk Factors: The distribution of infections in different age groups in males and

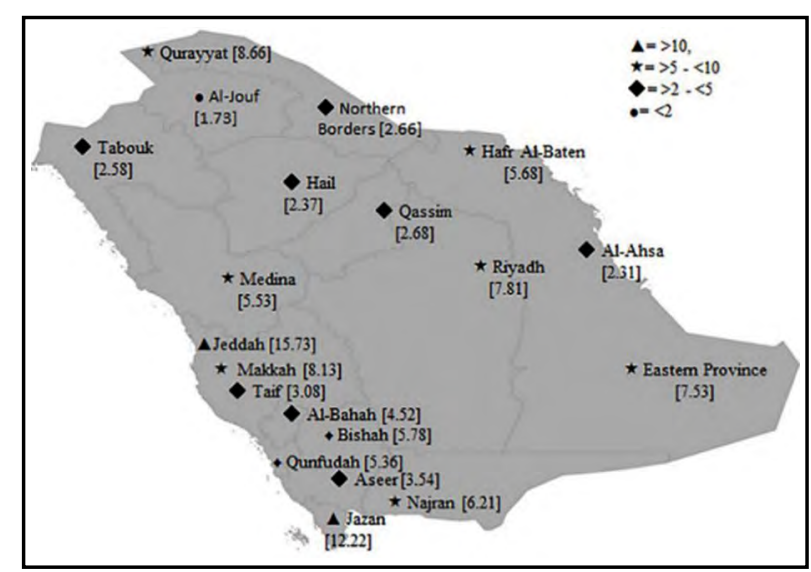

Fig.1: The Incidence Rate/100,000 of pulmonary tuberculosis in different regions of Kingdom of Saudi Arabia. Regions were divided into 4 different categories and indicated by symbols: $\boldsymbol{\Delta}=$ incidence rate $>10 / 100,000, *=$ $>5-<10 / 100,000, \bullet=>2-<5 / 100,000$ and $\bullet=<2 / 100,000$. 
Omar S. El-Masry et al.

Table-II: Age-wise incidence of Pulmonary Tuberculosis among Saudi and non-Saudi population.

\begin{tabular}{|c|c|c|c|c|c|c|c|}
\hline \multirow{2}{*}{ Age Group } & \multirow{2}{*}{ Age scale } & \multicolumn{2}{|c|}{ Saudi n (\%) } & \multirow{2}{*}{$p$-values } & \multicolumn{2}{|c|}{ Non-Saudi n (\%) } & \multirow{2}{*}{$p$-values } \\
\hline & & Male & Female & & Male & Female & \\
\hline Group I & $<15$ & $54(100)$ & $0(0)$ & & $0(0)$ & $0(0)$ & \\
\hline Group II & $15-<25$ & $424(95)$ & $21(5)$ & & $5(100)$ & $0(0)$ & \\
\hline Group III & $25-<35$ & $318(56)$ & $250(44)$ & & $162(100)$ & $0(0)$ & \\
\hline Group IV & $35-<45$ & $4(19)$ & $17(81)$ & 0.001 & $465(100)$ & $0(0)$ & 0.001 \\
\hline Group V & $45-<55$ & $0(0)$ & $3(100)$ & & $329(99)$ & $4(1)$ & \\
\hline Group VI & $55-<65$ & $0(0)$ & $0(0)$ & & $112(46)$ & $131(54)$ & \\
\hline Group VII & $\geq 65$ & $0(0)$ & $0(0)$ & & $15(6)$ & $229(94)$ & \\
\hline
\end{tabular}

females, Saudi and non-Saudi nationals. Table-II Amongst male Saudis, the highest percentages of infections were reported in the age range $<15,15$ 25 and 25-35 in order. In Saudi females, the highest percentage of infections were in age groups 4555 , followed by $35-45$. In this respect, there was a statistically significant difference between the number of infections in males and females in the above-mentioned age groups $(p=0.001)$.

The highest number of infections amongst male non-Saudi nationals was recorded in the age groups $25-35$ and $35-45$, followed by $45-55$. On the other hand, the highest female infections were in $\geq$ 65 then 55-65 age groups. Likewise, the difference was statistically significant between the number of infections in male and female non-Saudi nationals in these age groups $(p=0.001)$.

\section{DISCUSSION}

In the current study, the overall rate of incidence of pulmonary TB found to be $7.61 / 100,000$ in Saudi Arabia for the year 2018. Globally, the TB incidence rate is falling by roughly $2 \%$ a year. ${ }^{7,18}$ In 2019, the incidence of TB in Saudi Arabia was 9.9 cases/100,000. The incidence of tuberculosis in Saudi Arabia fell gradually from 19 cases/100,000 in 2000, to 9.9 cases/100,000 in 2019. ${ }^{6}$ The difference in the incidence of TB between genders could be attributed to sex hormones that may be responsible for modulating the immune response, which is necessary for fighting the pathogen and other infectious diseases. ${ }^{19,20}$ Recently, the mortality rate of TB was reported to be 22/1000 person-years being higher in males and elderly. Also, it has been suggested that the reactivation of latent MTB infection in elderly age could be due to immunosenescence and co-morbidities. ${ }^{21,22}$
In the current study, the number of cases of TB in males amongst the non-Saudi nationals was found to be higher than that in Saudi nationals; most likely because most of them came from countries with a high burden of TB. ${ }^{6}$ The highest number of infections amongst male non-Saudi nationals was recorded in the age groups $25-35$ and $35-45$, followed by $45-$ 55; this might be explained by the socioeconomic status, where in these age-groups there are a lot of unskilled workers who tend to live in crowded shelters, with poor sanitation and hygiene. ${ }^{23}$ These conditions make them susceptible for reactivation of latent TB. Expatriates arriving to the kingdom for work are not screened for TB, except for house workers and health professionals. ${ }^{24}$ The highest incidence rate of TB amongst non-Saudis, which was recoded in Jeddah, followed by Riyadh, may be associated with the higher proportion of non-Saudis in urban areas and industrial cities. Jeddah receives more than ten million foreign visitors every year for Hajj and Umrah. ${ }^{25}$

Another Saudi study reported low prevalence of TB and multidrug resistant TB over 17-year period in a single center. ${ }^{26}$ Having indicated that Saudi Arabia is a global destination and with continuous influx and outflux of people in and out from the country, there might be a chance of Saudi Arabia to become a spread point of infection in case TB incidence rises in a steady state. Therefore, we have to notify the readers that gulf health council (GHC) members that include Saudi Arabia have the highest prevalence of diabetes in the world, where the International Diabetic Federation (IDF) ranked five members of the GHC amongst the top 10 countries with high prevalence of diabetes. In this context, Saudi Arabia ranked third in the world by the IDF. Since diabetes has been found to increase TB risk, the high prevalence of diabetes in Saudi Arabia should be a warning sign. ${ }^{9}$ 


\section{CONCLUSION}

There was a significant difference between males and females regarding contracting the TB infection amongst both the Saudi and the non-Saudi nationals suggesting an association between gender and the increased risk of infection. Likewise, analysis of infection in different age groups suggested that the incidence rates in Saudis were recorded in younger age groups than in the non-Saudis, which is surprising. Importantly, we do not know whether non-Saudis are residents or visitors as it was not mentioned in the $\mathrm{MOH}$ database. In this respect, there should be a proper screening program for high-risk groups as well as a plan to investigate the risk factors that might be associated with the increased incidence of pulmonary TB. Altogether, these analyses and approaches would help health authority decision makers to establish policies and procedures to limit the infection and apply appropriate precautionary measures. To this end, this study analyzed the data of pulmonary TB incidence rates in 2018 where the data for other years were not reported on the $\mathrm{MOH}$ data repository. It would be more informative if we could obtain data for a longer period for the study to be more conclusive.

\section{Conflict of Interest: None.}

\section{Funding: None.}

Availability of data and materials: The data used to support the findings of this study are available freely on public domain of The Ministry of Health, Saudi Arabia. Open Data Portal. https://data.gov. sa/Data/en/organization/ministry_of_health

\section{REFERENCES}

1. Raviglione M, Sulis G. Tuberculosis 2015: Burden, challenges and strategy for control and elimination. Infect Dis Rep. 2016;8(2):33-37.

2. Lee JY. Diagnosis and treatment of extrapulmonary tuberculosis. Tuberculosis Resp Dis. 2015;78(2):47-55.

3. World Health Organization. (2018). Global tuberculosis report 2018. World Health Organization. https://apps.who.int/iris/ handle/10665/274453 Accessed on: Nov. 16, 2021

4. Maciuca S, del Ojo Elias C, McVean G, Iqbal Z. (2016) A Natural Encoding of Genetic Variation in a Burrows-Wheeler Transform to Enable Mapping and Genome Inference. In: Frith M., Storm Pedersen C. (eds) Algorithms in Bioinformatics. WABI 2016. Lecture Notes in Computer Science, vol 9838. Springer, Cham.

5. Lewandowski CM, Co-investigator $\mathrm{N}$, Lewandowski CM. WHO Global tuberculosis report 2015. The effects of brief mindfulness intervention on acute pain experience: An Examin Indiv Diff. 2015;1:1689-1699.

6. World Health Organization. (2020). Global tuberculosis report 2020. World Health Organization. https://apps.who.int/iris/ handle/10665/336069 (Accessed on: Nov. 16, 2021).
7. Ministry of health, Kingdom of Saudi Arabia. [2019]. Health Days 2019: World Tuberculosis (TB) Day. Retrieved from https:// www.moh.gov.sa/en/HealthAwareness/healthDay/2019/ Pages/HealthDay-2019-03-24.aspx Accessed on: Nov. 16, 2021

8. Yezli S, Memish ZA. Tuberculosis in Saudi Arabia: Prevalence and antimicrobial resistance. J Chemother. 2012;24(1):1-5.

9. Saati AA, Khurram M, Faidah H, Haseeb A, Iriti M. A Saud Arabian Public Health Perspective of Tuberculosis. Int J Environ Res Public Health. 2021;18(19):10042. doi: 10.3390/ ijerph181910042

10. World Health Organization. (2017). Global tuberculosis report 2017. World Health Organization. https://apps.who.int/iris/ handle/10665/259366 (Accessed on: Nov. 16, 2021).

11. Nabarro L, Morris-Jones S, Moore DAJ. Infections Acquired by Airborne Transmission. Peter's Atlas Trop Med Parasitol. 2020:244-281. doi: 10.1016/B978-0-7020-4061-0.00004-2

12. Honarvar MR, Charkazi A, Mirkarimi K, Sheikhi M, Kamalinia HR, Rahim Arbabi E. Eleven year epidemiological study of tuberculosis in Golestan Province, Northern of Iran. Iran J Public Health. 2020;49:563-569.

13. Ahmed MM, Velayati AA, Mohammed SH. Epidemiology of multidrug-resistant, extensively drug resistant, and totally drug resistant tuberculosis in Middle East countries. Int J Mycobacteriol. 2016;5:249-256.

14. Al Awaidy ST, Khamis F. Tuberculosis in gulf health council member states: Opportunities and challenges towards TB elimination. Oman Med J. 2018;33:181-183.

15. Metersky ML, Schluger NW. New Guidelines for the treatment of drug-susceptible tuberculosis from the American thoracic society, centers for disease control and prevention, and the infectious diseases society of America: Now comes the hard part. Am J Respir Crit Care Med. 2016;194:791-793.

16. Aljadani R, Ahmed AE, Al-Jahdali H. Tuberculosis mortality and associated factors at King Abdulaziz Medical City Hospital. BMC Infect Dis. 2019;19:1-7.

17. Workneh MH, Bjune GA, Yimer SA. Diabetes mellitus is associated with increased mortality during tuberculosis treatment: A prospective cohort study among tuberculosis patients in SouthEastern Amahra Region. Ethiopia Infect Dis Poverty. 2016;5:1-10.

18. Glaziou P, Sismanidis C, Floyd K, Raviglione M. Global epidemiology of tuberculosis. Cold Spring Harb Perspect Med. 2014;5(2):a017798. doi: 10.1101/cshperspect.a017798

19. Alateah SM, Othman MW, Ahmed M, Al Amro MS, Al Sherbini $\mathrm{N}$, Ajlan HH. A retrospective study of tuberculosis prevalence amongst patients attending a tertiary hospital in Riyadh, Saudi Arabia. J Clin Tuberc Other Mycobact Dis. 2020;21:100185.

20. Nhamoyebonde S, Leslie A. Biological differences between the sexes and susceptibility to tuberculosis. J Infect Dis. 2014;209(Suppl 3):S100-S106. doi: 10.1093/infdis/jiu147

21. Byng-Maddick R, Noursadeghi M. Does tuberculosis threaten our ageing populations? BMC Infect Dis. 2016;16:119. doi: 10.1186/s12879-016-1451-0

22. Wang SH. The influence of increasing age on susceptibility of the elderly to tuberculosis. Open Longevity Sci. 2012;6(1):73-82.

23. Noykhovich E, Mookherji S, Roess A. The Risk of Tuberculosis among Populations Living in Slum Settings: A systematic review and meta-analysis. J Urban Health. 2019;96:262-275.

24. Al-Orainey I, Alhedaithy MA, Alanazi AR, Barry MA, Almajid FM. Tuberculosis incidence trends in Saudi Arabia over 20 years: 1991-2010. Ann Thorac Med. 2013;8(3):148-152. doi: 10.4103/1817-1737.114303

25. Zumla A, Saeed AB, Alotaibi B, Yezli S, Dar O, Bieh K, et al Tuberculosis and mass gatherings-opportunities for defining burden, transmission risk, and the optimal surveillance, prevention, and control measures at the annual Hajj pilgrimage. Int J Infect Dis. 2016;47:86-91. doi: 10.1016/j.ijid.2016.02.003

26. Alateah SM, Othman MW, Ahmed M, Al Amro MS, Al Sherbini $\mathrm{N}$, Ajlan $\mathrm{HH}$. A retrospective study of tuberculosis prevalence amongst patients attending a tertiary hospital in Riyadh, Saudi Arabia. J Clin Tuberc Other Mycobact Dis. 2020;21:100185. doi: 10.1016/j.jctube.2020.100185 